Vol. 4, Issue.6, Nov-Dec 2021, page no. 361-384

To cite this article: Duc Anh Duong and Thi Lan Phuong Nguyen (2021). USING MOCK CONFERENCE TO TEACH CONSECUTIVE INTERPRETING - A CASE STUDY AT VINH UNIVERSITY, International Journal of Education and Social Science Research (IJESSR) 4 (6): 361-384

\title{
USING MOCK CONFERENCE TO TEACH CONSECUTIVE INTERPRETING - A CASE STUDY AT VINH UNIVERSITY
}

\author{
Duc Anh Duong ${ }^{1}$ and Thi Lan Phuong Nguyen ${ }^{2}$ \\ ${ }^{1}$ Vinh University, Department of Foreign Languages, \\ 182, Le Duan, Vinh city, Vietnam \\ (Corresponding author) \\ ${ }^{2}$ Vinh University, Department of Foreign Languages, \\ 182, Le Duan, Vinh city, Vietnam \\ DOI: http://dx.doi.org/10.37500/IJESSR.2021.4627
}

\begin{abstract}
Using mock conferences to teach consecutive Interpreting has been discussed so far to increase students' interpreting skills by scholars around the world. However, little research has been done to investigate the effectiveness of this approach in Vietnam. This study's objective is to identify whether mock conferences can help students increase their interpreting competencies such as concentration and professionalism better than traditional classrooms, which focuses on listening.
\end{abstract}

Data were collected through web-based questionnaires from 35 third-year graduate trainees of Interpreting. The trainees rated MCs as good, favorable, and motivating experiences, and their ratings were positively correlated to frequencies of their Interpreting at MCs. Findings indicate that skills concerning professionalism, psychological competence, strategic competence, and many other nonlinguistic dimensions could be better developed at MCs than in traditional interpreting classes.

KEYWORDS: mock conference, consecutive interpreting, professionalism development, teaching methodology

\section{INTRODUCTION}

Interpreting has always been an essential profession for countries, especially when one considers that the world is becoming increasingly integrated. Translation and interpreting training have become particularly significant since Vietnam become an official member of World Trade Organization and the the 12th member of TPP (Nguyen N. T., 2016). Currently, around 60 universities in Vietnam are training Interpreting and translation courses. Some universities based in Ho Chi Minh city such as Ho Chi Minh Open University, Vietnam National University Ho Chi Minh city have made Interpreting and translation become a major in their curriculum. Despite the fact that the syllabus and curriculum have been designed for long, the standard mode of teaching is limited in term of activities that teachers 
conduct in the classroom (Pham, 2015). Most lecturers at HCM Open University teach in their own way, which is based on their experience. Thus, it is become urgent to find out an effective solution to guide Interpreting.

According to Nguyen (2016), there are some limitations of teaching interpreting at universities in Vietnam. First, the teaching of Interpreting focused firmly on teaching listening skills. Second, the course books used for education are rare. They focus on providing materials rather than showing the techniques for exercises. Regarding this point, Le (2016) commented there has been no concensus on the standard of teaching materials. According to a survey conducted by Le et al. (2016), 67 out of 100 students who had been asked said that the training courses at universities had provided enough knowledge and skill needed for their profession. They felt little confident in their major after graduate. Similarly, Nguyen et al (2016) found that most of the teachers of interpreting concentrated on theory, rather than implemented activities that were practical. The content of the course went around some common topics and has not met the demand of the market.

In the world, professional conference interpreting was originally associated with international gatherings at the highest level (such as the Nuremberg Trials), it has evolved throughout the years and now covers almost all fields of multilingual and intercultural communications (Pöchhacker F.,1992) ranging from large diplomatic meetings to more technical workshops on agriculture, environment, energy, etc. Moreover, as with many other professions, conference interpreting has also become a subject of research in academia. The result has been the development of Interpreting Studies as an academic discipline, concerned with all aspects pertaining to interpreting whether in theory or practice; evidence of this is found in the growth of specialised thematic research areas such as conference interpreter training, as well as the numerous articles, books and journals available on a wide range of topics. While this indicates an academic discipline evolving well alongside the profession, compared to other disciplines, it is only in the past few years that Interpreting Studies has become this dynamic. Despite this considerable progress with academization, (Pöchhacker F, 2004) notes, however, that Interpreting Studies still has a modest research output internationally.

Discussing on the method of teaching interpreting, international scholars seem to agree that the situated approach would specifically appropriate. e 2004, Hatim and Mason 1997, Napier 2006, Roy 2000, Setton 2006, as cited in Li, 2015 agreed that Interpreting is a highly situated professional activity which is an instructional approach developed by Jean Lave and Etienne Wenger in the early 1990s. Situated learning suggests that learning takes place through the relationships between people and connecting prior knowledge with authentic, informal, and often unintended contextual learning. In this situation, a student's role changes from being a beginner to an expert as they become more active and immersed in the social community where learning often is "unintentional rather than deliberate" (Oregon Technology in Education Council, 2007). One of the situated teaching practices in current interpreter training is organising mock conferences (MCs). 
The importance of MCs has been repeatedly mentioned in the Interpreting Studies literature, however, little has been done to further its systematic design and teaching effect. Against such a background, this thesis attempts to fill the gap by sharing experiences of designing MCs and exploring their teaching effect.

\section{LITERATURE REVIEW AND HYPOTHESIS}

\subsection{Interpreting training in the world}

Interpreting is a compulsory subject in many universities' curriculum whose training program is to provide the labor market with interpreters, translators or officers working for international and foreignrelated organizations. Although it is one of the oldest professions in the world, the training professional interpreters has just begun in recent decades, relatively short when compared to the history of interpreting which is known to date back to Ancient Egypt during the 3rd millennium B.C. (Access 2 Interpreters, 2014). Since World War II, the training interpreting has been carried out at universities and colleges to replace the previous traditional way of training which was regarded as unsystematic and unprofessional.

At first, there were some universities in some German speaking countries (Heidelberg in 1930, Geneva in 1940 and Vienna in 1943) that specialized in training interpreting to accommodate the rapid demand of the War. After the World War II, the military requirement of weapon production, and the urgent need of intepreting for Nuremberg trials engendered many schools that trained interpreters in the U.S. and Europe, for example, Graz and Innsbruck in 1946, Germersheim in 1947, Georgetown University in 1949. Different from the West Europe, the East Europe started training intepreters sooner and integrated the training in the curriculum. Most of the schools in Europe are members of IUTI (Conférence Internationale Permanente d'Instituts Universitaires de Traducteurs et Interprètes) established in 1964 and highly specialized. The IUTI now comprises more than 30 members endeavour to ensure the high quality by conducting training programs in more than 300 institutions in the world, which takes up to $10 \%$ of market segmentation in the world.

However, beyond West Europe, the training intepreters professionally developed rapidly and the number of interpreting institutions overtook that of West Europe during 1970's. The root cause of this change was political and economic conditions. European countries trained interpreter for the sake of forming an union, however, other countries trained interpreters for the need of globalization and economic development. (Tien, 2017)

The intepretation training has undergone a major change in the form and mode (Tien, 2017). The Interpreting program has shifted from a special training course to elite interpreters to become a normal course at universities. One explanation for this trend could be high unemployment rate for language students, coupled with the increasing popularity of English. Many language teachers opt for doing 
Interpreting as a side-job. In Canada, Australia and America, due to the government policy that supports minor languages, Interpreting are more important than teaching language as interpreters play a crucial role at the course, hospitals and immigrant departments.

In China, described by Liu (2013), interpreting courses are part of higher education curriculum, and belongs to language departments of each university. Although Bejing Language University started to offer a Master Degree in Translation and Interpreting, until from 2017 the school has brought down the course to B.A. level (Tien, 2017).

\subsection{Interpreting training in Vietnam}

In Vietnam, the interpreting training course at universities began in the late 90's. Before 1990, interpreting programs were offered scatterly at some schools of languages, commerce and diplomacy. The courses focused heavily on teaching languages only and there were few courses in which students could participate in practicing interpreting.

After 2000, some universities started to offer Bachelor's degree in Interpreting, however, the curriculum were somewhat haphazardly without solid research foundation (Tien, 2017). Most of the courses comprise two years training four skills and another two years training translation and Interpreting. At first, students graduated from these universities would receive a Bachelor's Degree in Foreign Language, minor in Interpreting-Translation studies, however, Interpreting-Translation studies was eliminated from the title and the degree was renamed as Bachelor's Degree in Language studies.

Translation is an art that requires a lot of practice and expertise in both the source language and the target language. According to Searls-Ridge (2000), good translation skills are not an innate ability, but they require a constant practice and diligence. For lecturers, Razmjou (2004) asserts that even though lecturers have obtained an extended knowledge about translation theory and also good translation practice skills, it is not necessarily enough to train students. Only with meticulous and systematic teaching methods, teachers can train students to become efficient translators and interpreters. The more difficult problem for teachers is that how teacher gives feedbacks to students' translation and interpreting assignment. First, the language of assignment should be done correctly. However, being correct is not enough, the aesthetic of the work also matters.

Nguyen Thi Nhu Ngoc, Nguyen Thi Kieu Thu, and Le Thi Ngoc Anh (2016) conducted a survey by interviewing 28 lecturers (teachers) at 10 universities across the country and found that, most of translation and interpreting lecturers provide exercises and ask students to analyze the structure and vocabulary and then translate. Or they ask students to analyze some translated phrases or sentences, and then come up with other translations. As for the interpreting courses, the teacher will tell the students the topic for students to find information on the Internet, then let the students listen to each 
paragraph and interpret. After that, teachers explain and instruct more skills to students. Some teachers also let students work in groups to discuss the content to be translated. The group of researchers also found that most of the teachers applied language teaching techniques to teaching interpreting and translation courses. Teachers often ask students to read / listen carefully to the text before translating. Grammar and vocabulary are the two skills that are most interested in students' translations. Moreover, the majority of teachers give answers as the final translation, only a few let students give their own different answers and discuss. From the perspective that interpreting is an art (Zaixi, 1997), translation certainly cannot be a single answer because there are so many different expressions of language during translation, not always one. unique (Pham, 2016).

Nguyen Quang Nhat (2016) explored the teaching situation of interpreting and translation courses in some universities and found some limitations in the teaching method of this subject as follows. Firstly, the teaching method of translation and interpreting focuses mainly on teaching listening. Second, the interpreting coursebooks are limited, mainly provide materials but not details technical instructions. On this point, the research team Nguyen Thi Nhu Ngoc, Nguyen Thi Kieu Thu, and Le Thi Ngoc Anh (2016) also commented that the curriculum and learning materials of this subject can be considered as the weakest feature and do not follow to a common standard. The translation and interpreting textbooks are mainly distributed internally, and do not meet a unified standard.

In terms of curriculum and training team, Le Thi Thanh Thu and colleagues (2012) found that nearly $67 \%$ of graduates of the Translation and interpreting major from universities in Ho Chi Minh City assessed that the training program does not provide the required amount of knowledge and skills in the major, and they do not feel confident after graduation. In addition, they acknowledge that very few instructors of translation and interpreting have the specific knowledge to train them. Similarly, Nguyen Thi Nhu Ngoc and colleagues (2016) also concluded that the majority of teachers have not yet received specialized training in translation and interpreting. Many teachers favor theoretical training and offer few practical activities close to translation services in society. Training content often revolves around familiar issues, slow to innovate and not keeping up with market demand. Pham Vu Phi Ho and Phu Thi Kieu Bu (2013) conducted a survey of 4th year students preparing to graduate from this major and found similar results with Le Thi Thanh Thu et al (2012) that this specialized training program at Ho Chi Minh City University of Technology has not equipped the necessary knowledge and skills for students to integrate into society. They are also dissatisfied with the curriculum at the faculty because the content of material is not updated and the teaching method is monotonous.

In terms of skills in using tactics in the translation and interpreting process, Huynh Van Tai (2016) gives some limitations of students in the process as follows. Firstly, students often perform their translation and interpreting work according to their instinction and ignore doing a deep analysis and careful study of the translated discord. Second, students do not understand the register of language used in each type of text. Third, they lack consistency, coherence in the passage, and sometimes there 
is a contradiction in the very passage. And, finally, they are insufficient in background knowledge. Pham Vu Phi Ho and Phu Thi Kieu Bui (2013) also found that the students majoring in translation and interpreting felt that their language command was incompetent and they were not equipped with adequate skills in the translation process. In fact, translation and interpreting are difficult subjects not only for students but also for teachers because they require students to obtain a wide range of specialized knowledge, vocabulary, grammar structure, and an amble understanding about culture, and even mother tongue (Pham, 2015).

Despite its essential position in the curriculum, teachers of this field encounter a number of challenges in teaching this subject. First, textbooks and other related resources are not available in both domestic and international markets. Teachers then use their own experience in designing materials for in-class use. Some existing course books about Interpreting are not appropriate for the context of Vietnam; there is not enough input for the Vietnamese-English interpreting practices. The practices for EnglishVietnamese Interpreting are not in levels, i.e. for pre-intermediate or advanced learners; therefore, they may be either too easy or too tough. Moreover, there are few domestic seminars and conferences in this field for teachers to share their expertise and experience in teaching Interpreting. It seems each university has its own model in teaching the subject. Finally, not all interpreting teachers are officially trained to teach the subject. (Tran , 2019). Only some big institutions like Hanoi University, College of Foreign Languages - Da Nang University have sent their teachers abroad for attending short courses about Interpreting and how to teach it (Nguyen N. T., 2016). Lecturers at Department of Foreign Languages at Vinh University, in particular, also encounter the above-mentioned obstacles.

\subsection{Interpreting as a situated learning activity}

Interpreting Studies scholars agree that Interpreting is a contextualised activity. Interpreting is a service of intentional, interlingual, intercultural and interpersonal communication situated in and constrained by a professional context (Hatim \& Mason, 1997). Unlike a translation activity where the writer, translator and target readers are distant from one another in terms of time and space, Interpreting is performed in live situations where the interpreter shares the same environment with the speaker and listeners, and has access to the immediate and shared context which keeps unfolding and changing as the communicative event proceeds; if it is time that makes solving translation problems possible, it is access to the immediate context that enables the interpreter to compensate for the temporal constraints (Setton, Context in simultaneous interpretation, 2006).

Angelelli, (2016) suggests that interpreters are physically and emotionally present in the communicative contexts in which they work, expressing information and affect, controlling the flow of communication, and facilitating mutual trust and respect, and that their roles change depending on the needs and constraints imposed by the contexts. The contextual cues, such as paralinguistic and extralinguistic signs, are a resource that should be taken advantage of selectively and strategically by 
interpreters. If Interpreting is a highly contextualised task, the overarching goal of interpreter education is supposed to develop trainees' competence to perform Interpreting as it is ( $\mathrm{Li}, 2015)$.

\subsection{Situated learning through simulations: The use of MCs}

Simulations prepare trainees many opportunities to practice, bring the benefits of situated learning to traditional classrooms by providing access to more authentic contexts and facilitating interactions between learners and experts, and maximise the efficiency of T\&I programmes in preparing interpreters for the market (Herrington \& Oliver, 2000)

In simulations, though learning environments are simulated, they are replicas of reality and participants behave and act as if they were real. Simulations protect learners from otherwise severe consequences of mistakes, lower their anxiety level by providing a less threatening environment, provide scaffolding and feedback from instructors and peers and help to meet academic and personal growth objectives (Herrington \& Oliver, 2000).

In interpreter education, such simulations usually take the form of MCs. MCs are important formats of interpreting teaching (Lin W., 2013)

MCs have more advantages in facilitating skill acquisition. In traditional interpreting classrooms, though there might be some elements of simulation, the instructor mainly uses audiovisual media, depriving trainees of the contexts vital for oral communication and plays the roles of both speaker and listener or gets other students to give speeches, which substantially reduces the authenticity and diversity of lifelike situations. All participants understand the two languages being used, without the real need for overcoming language barriers for communication. By contrast, $\mathrm{MC}$ reflects the pragmatic aspects of orality and interlinguistic communication and is a valuable pedagogical means to evaluate if trainees are able to interpret different types of speech acts. It helps trainees experience the real world under controlled circumstances. It has a positive backwash effect because it stimulates trainees' enthusiasm and autonomy, though trainees show different degrees of anxiety at the initial stage (Lin, Davis, \& Liao, 2004). It helps trainees acquire skills better, motivates them to learn Interpreting by presenting the real need to overcome linguistic barriers that is absent in traditional classrooms, and prepares them for the market.

Organising MCs plays an important role in an interpreting programme. As illustrated in Figure 1, the interpreting skill development process can be divided into three phases: initial skill development in traditional interpreting classrooms, skill sharpening through simulated practices and internships, and skill maturity phase in the form of on-the-job learning after graduation. The three phases are progressive. The end of one and the start of the next are not prescriptive, depending on trainees' progress in specific teaching contexts. 
Figure 2.1: Three phases of interpreting expertise development

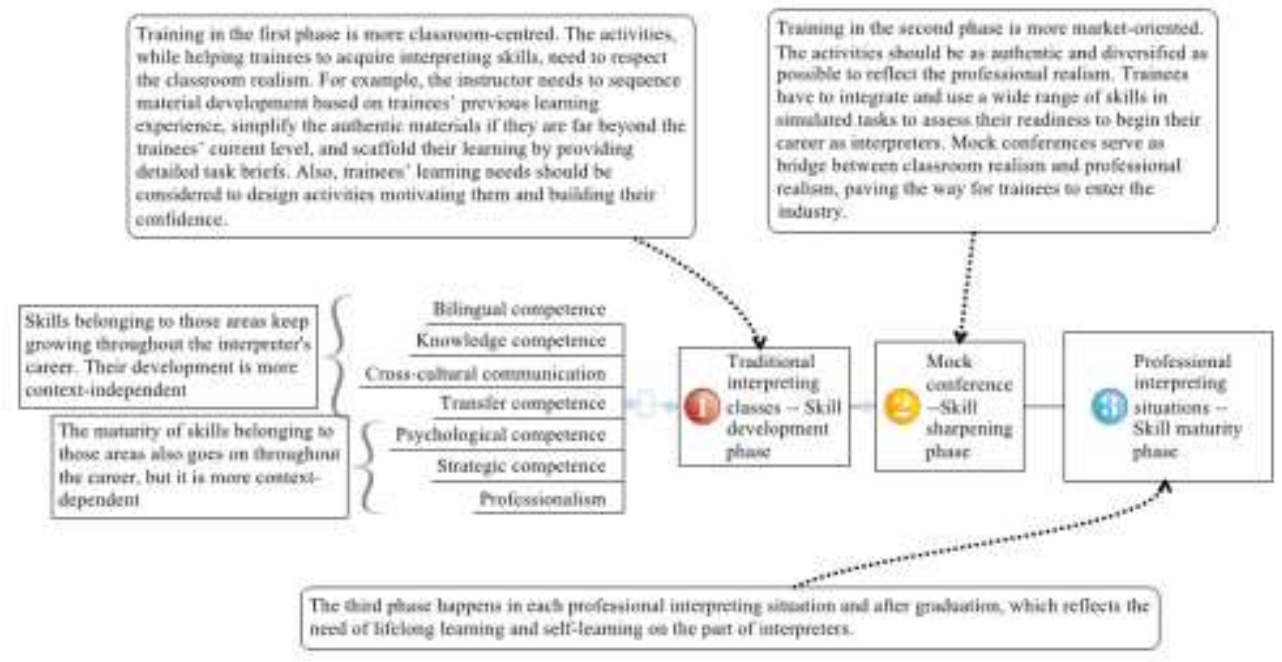

Those three phases presented here are generally consistent with two of the three phases proposed by Mikasa (2013). Drawing on in-depth interviews with professional interpreters and process- and experience-based accounts of interpreter skills and competencies, she found that professionals develop their competences progressively through three phases in the course of their working life: general education phase (prior to training in interpreting programmes), interpreter training phase (in interpreting-specific courses) and professional on-the-job phase (after graduation). Language-related competences are mainly developed to a satisfactory level in the general education phase and further cultivated during the interpreter training phase and professional on-the-job phase. Interpreting-specific competences in comprehension, transfer and production are mostly developed in the interpreter training phase, and maintained and sharpened in the professional on-the-job phase. Business-related competence - for example, business know-how, professional codes, and establishing and maintaining good customer contact and relations - is cultivated mainly in the professional on-the-job phase. AlblMikasa's (2013) general education phase is beyond the focus of interpreter education and therefore is not included in the current discussion. The skill development phase proposed in this article corresponds to Albl-Mikasa's (2013) interpreter training phase, and the skill maturity phase to her professional onthe-job phase. This thesis considers that there is a gap between her interpreter training phase and professional on-the-job phase which can be filled by training programmes to maximise learning outcomes and ensure the match between training and market needs. Therefore, the skill sharpening phase which takes the format of MCs is added.

The first phase, or initial skill development in traditional interpreting classrooms, is more classroomcentred. At the beginning of interpreter education, trainees are not adequately ready to perform authentic tasks. Emphasis may be placed on competences that can be developed in a less contextualised environment; for example, linguistic, textual and cultural competences, transfer, research, and general 
and subject-specific knowledge. Instructors need to complement their personal professional experience and intuition with other considerations; for example, the cognitive challenges of interpreting tasks, appropriateness of material selection, variation in students' temperaments and development, and when to focus on process and when on product (Setton, 2006).

In the second phase, or skill sharpening through simulated practices, students should learn to be more user-oriented and market-oriented. When students begin to show abilities to deal with authentic tasks, the teacher will then organise MCs where students continue to develop other competences; for example, professionalism, psychological competence, strategic competence, and many other nonlinguistic dimensions (e.g. interpersonal skills, problem-solving skills, negotiation, resourcefulness, reflectiveness, etc.), through contextualised practice. With their psychological maturity, language ability and general knowledge required to complete their training, they are ready to be trained for entry into the profession, compared with undergraduates who need to focus on enhancing language skills and general and subject-specific knowledge (AIIC Training Committee 2006). Additionally, they have remarkable career orientation and strong motivation to be involved in professional experiences (Lin 2013). They need to integrate a wide range of skills and use them in simulated tasks to check their readiness to begin their career as interpreters. Activities at this stage should be as authentic and diversified as possible to reflect the professional realism. It may begin by inviting monolingual speakers to classrooms (Ardito 1999; Tsuruta and Naito 2011) and then move on to organise more formal MCs. The use of MCs with scaffolding from peers, teachers and experts, if possible, is more appropriate to prepare students for real-life scenarios. It serves a bridge between classroom realism and professional realism, paving the way for the trainees to enter the industry. MCs can be extended into internships with supervision; for example, in the dumb booths of recruiting organisations.

The third phase, or skill maturity phase in the form of on-the-job learning after graduation, happens out of classrooms and in each professional interpreting situation, reflecting the need for lifelong learning and self-learning. When students are adequately prepared to interpret authentic tasks after intensive training through MCs and internships, they will continue to develop their skills on the job. The role of the teacher is then reduced to a minimum, mirroring the importance of cultivating students' ability of reflectiveness, self-concept and many other skills of professionalism in the MC phase.

\subsection{Designing MCs: principles and procedures}

In the above section, guidelines for applying situated learning in instruction have been summarised based on provisional conclusions from the literature. In this section, those guidelines will be materialised into specific principles and procedures for organising MCs which were used to inform and design the current survey. Based on the situated learning principles, the author would like to present seven principles which have been applied in his own teaching context: 
(1) Student-centred learning environment. Skills are not transmitted directly from the instructor to students. The instructor is a manager and a facilitator and a source of advice and encouragement. A humanistic approach to learning is essential for students to have confidence and self-esteem (Tomlinson 2012), which is important for maintaining their motivation as evidenced by Timarová and Salaets (2011). Therefore, the author of this article thinks, as Lim (2003) does, that it is not advisable to interrupt and give feedback during MCs (Lim 2003). Instead, the instructor may take notes on students' performances and provide feedback to complement their self-reflections during the debriefing phase.

(2) Authenticity. Students are briefed with the what, who, why, when and where, for the job at hand, allowing for preparations (Gile 2002). Students need to dress appropriately, work with real conference speeches and serve real clients (Gillies 2013). It is not suggested that instructors should reduce the complexity of assignments. Speakers and (some) conference representatives need speak only one of the working languages and have the interpreted language as the only source of information, which motivates the students to play their roles as mediators because the real need to help achieve communication is felt, and their feedback will be more constructive (Lee 2005). MCs need to involve various speakers (native and non-native speakers, with and without accents, etc.), topics (economics, business, education, culture, law, etc.) and speech formats (seminar discussions; conference presentations with and without visual aids; spontaneous, recited and read-out speeches; etc.) to prepare students for the real market. Working scenarios (community, seminar and conference settings) should also be diversified. Different interpreting settings call for different abilities on the part of the interpreters; for example, the dialogic mode - equal amount of work into both languages, possibility of controlling the information flow, and maximum potential for different backgrounds between the parties in community interpreting - in contrast with mostly monologic mode: (mostly) work into one language, inability to control the speaker, and minimum potential for different backgrounds between the parties in conference interpreting settings (Angelelli 2000). Interpreting modes (consecutive, simultaneous, sight, whispering, etc.) should vary. For example, consecutive interpreters serve a social function to interact face to face with the participants and are more highly visible than simultaneous conference interpreters (Baxter 2012). The realities of local market needs should also be taken into account (Tsuruta and Naito 2011).

(3) Scaffolding. The instructor provides task briefs to effectively activate and refresh students' schemata (background knowledge), assisting students' understanding of the original text (De Laet 2010). Briefing is important for interpreters to know ample information about and have a macro-level understanding of the communicative context and to do a good job (AIIC 2011; Kalina 2000). Other forms of scaffolding include instructor-led self-assessment, peer assessment, and constructive criticism from the audience, clients and instructors (Fernández Prieto and Sempere Linares 2010). 
(4) Reflection. Reflection is a crucial skill for developing attitudinal and strategic competences (Fernández Prieto and Sempere Linares 2010). Students should be given opportunities to introspect on their performances and understand why they acted the way they did after MCs (Lim 2003). Selfassessment cultivates meta-cognitive skills (self-monitoring, self-reflection, independent thinking, autonomous learning, etc.), and makes learning and teaching more targeted because it informs learners about their own strengths and weaknesses and informs the teacher about students' progress and needs (Lee 2011; Postigo Pinazo 2008). Rubrics based on instructor and student discussion should be generated to assist their assessment.

(5) Interactive and collaborative relationships. In preparing for MCs, students work in teams to search relevant background information and build glossary lists. At the end of MCs, peer assessment is encouraged to give one another feedback. Students are recommended to share their experiences (embarrassing moments, emerging problems and solutions, lessons learnt, etc.) with everyone present at the MCs.

(6) Access to a community of practice. The audience and clients are invited to give feedback on students' performances in terms of linguistic and cognitive skills, interpersonal skills, and professionalism. Instructors or experts give feedback about where the students are, where they need to be, the possible reasons for certain failures, and how to make improvement. Such constructive criticism is of great value in building students' identities as professionals (Nicholson 1993; Tsuruta and Naito 2011).

(7) Authentic assessment. Assessment should be integrated with situated learning so that the situation provides both instructional and assessment opportunities and information (Young 1993). As argued previously, interpreting is a highly contextualised activity. Therefore, to check if students have developed all interpreting competences, the assessment plan needs to take into account situational or contextual parameters. As typical contextualised activities, MCs may be better indicators of students' level of interpreting skills compared with traditional less contextualised classroom exercises. The author of the current article, based on his personal teaching and interpreting experiences, tends to agree with Viaggio (1999) when he writes that interpreting ensures fluid and effective communication for the specific task in hand under specific objective and subjective circumstances, obstacles and limitations, and that any voluntary or involuntary omissions, additions, compressions, adaptations and awkwardness of expressions are justified if they help interpreters save processing effort which would otherwise not be available, though this is a bold claim. Simply put, the evaluation of interpreting quality cannot be relied absolutely on consistence between the source and target speech without taking into account situational parameters related to the speaker, noises, equipment or other emergencies in the communicative context. For example, an experienced interpreter with adequate research on the conference background and preparation of available documents or PowerPoint slides, when interpreting for a well-trained public speaker with standard pronunciation, appropriate volume and 
effective and legible visual aids, can reduce omissions, compressions and awkward expressions to a minimum. However, under extreme circumstances, if the same interpreter works for a non-native speaker who has a strong accent and poor grammar and delivers his or her speech on a specialised topic with overcrowded PowerPoint slides in a fast-paced manner, he or she will strategically resort to omission and compression, voluntarily or involuntarily, so that his or her limited processing capacity can be saved to deal with the constant influx of the source speech. Usually, it is the interpreter's ability that determines interpreting quality. However, in extreme situations, context-specific parameters that are sometimes beyond the interpreter's control may affect interpreting quality. Professionalism, psychological competence, strategic competence and many other non-linguistic dimensions of interpreter competence can be better assessed in contextualised practices (Fernández Prieto and Sempere Linares 2010). The assessment of interpreting needs to be situated to evaluate not only linguistic and cognitive skills but also other skills - for example, interpersonal, social, problem-solving, etc. (Angelelli 2004) - and to be authentic to ensure that the criteria correspond to those used for assessing real-life tasks (Chen 2009).

\section{Based on the principles above, six procedures can be formulated:}

(1) Briefing: event theme, background, speaker profiles, date, agenda, resources, tips for preparation, etc.

(2) Preparation: background and documents research, analysis of parallel and comparable texts, glossary building, sharing of information and discussion, labour division (who is going to interpret which speaker), etc.

(3) Participant training: last chance to make clarifications before the $\mathrm{MC}$, checklists of rubrics generated through students and instructor discussion to empower participants to evaluate their own weaknesses and strengths, etc.

(4) MC day: students take turns to interpret.

(5) Debriefing: self-assessment, peer assessment, clients and audience feedback, and instructor or expert feedback and suggestions.

(6) Using assessment results to inform teaching and learning.

\section{RESEARCH METHODOLOGY}

\subsection{Situation of the research}

Vinh University is one of the largest higher educational institutions in the North-Central region of Vietnam. It is the training center of highly skilled human resources for the region and the country nationwide. Established in 1959 as a didactic school, Vinh University has grown to be a multi-level institution (from pre-school level, high school to college, graduate school), multi-sector (54 undergraduate, 37 master's degree majors, 16 doctoral training programs) with more than 35.000 students. Currently, Vinh University is one of ten key institutions participating the National Languages Project. (Vinh University, 2019) 
Department of Foreign Languages, established in 1994, is a prestigious department specialized in teaching and training foreign languages, translation and Interpreting in Vietnam. The Department, is one of the ten language centers approved by Ministry of Education and Training to organize language proficiency tests and grant certificates of competency based on CEFR levels. (Department of Foreign Languages, 2019).

The course Interpreting I accounts for three credits in the teaching curriculum at the Department of Foreign Languages Department. Third-year students majoring in English studies are required to attend the course three periods a week. The content of training course comprises many topics that focus on equipping students with knowledge on memory, note-taking, and public speaking. In terms of training practical skills, the course emphasizes on training students consecutive interpreting skills through short conversation, speeches, news, and talks about cultural customs, economics, education, healthcare, etc. (Nguyen P. L., 2017)

There are three goals in the training course. The first one is aimed at arming students with basic knowledge of Interpreting, enhancing their understanding of some common topics related to countries, peoples, cultural customs, populations, economics, news, education, health, etc. The second one addresses some basic skills of consecutive Interpreting, which includes: memory skills, note-taking skills, linguistic skills, public speaking skills, autonomous learning skills, co-operative skills, and research skills. The third goal of the course is to help students have a good attitude of the job, the role of interpreters, and finally the code of conduct of an interpreter. (Nguyen P. L., 2017)

\subsection{Research questions}

The research was designed and conducted to investigate the learning effect of MCs on students' performance and to measure the students' perceived value. Two research questions are listed as follows:

1. What skills can be acquired better at MCs than in traditional interpreting classes?

2. Do MCs improve the students' interpreting performance?

The informants of the study were 70 students who are in their third year who took part in the course Interpreting I. 35 of them were asked to take part in the treatment group. The other half participated in control group in which they received no treatment, and followed the conventional way of teaching. A pre-test and posttest were designed to evaluate students' interpreting skill in both groups. In the treatment group, students were free to choose the topics they wanted to work with for the mock conferences. After the experiment, they were asked to provide feedbacks, as well as answer a webbased survey. 
Vol. 4, Issue.6, Nov-Dec 2021, p no. 361-384

The control group is described in terms of gender, summarised in the table below:

Table 3.2: The control groups' background information

\begin{tabular}{|c|c|c|}
\hline Participants & \multicolumn{2}{|c|}{ Control Group } \\
\hline Number & \multicolumn{2}{|c|}{$35(100 \%)$} \\
\hline Gender & Male & Female \\
\cline { 2 - 3 } & $4(11,4 \%)$ & $31(88,5 \%)$ \\
\hline
\end{tabular}

Likewise, the experimental group is described in terms of gender, summarised in the table below:

Table 3.3: The experimental group's background information

\begin{tabular}{|c|c|c|}
\hline Participants & \multicolumn{2}{|c|}{ Experimental Group } \\
\hline Number & \multicolumn{2}{|c|}{$35(100 \%)$} \\
\hline Gender & Male & Female \\
\cline { 2 - 3 } & $3(8,57 \%)$ & $32(91,43 \%)$ \\
\hline
\end{tabular}

\subsection{Instruments for data collection and procedures}

In order to acquire a sufficient collection and reliable and valid data for the study, the researcher conduct instruments: questionnaire and pre-test - post-test.

To accomplish the purpose of the study, the following procedures were pursued:

First, a survey was conducted asking a hundred students who major in English and are in their final year at Vinh University to provide their assessment on translation/interpreting courses that they have attended. The survey aims at investigating type of material needed for the training course, which skills and areas of knowledge that should be covered.

Second, a poll was initiated among a group of students who major in English and are in their third year at Vinh University. They were asked to choose the topics in accordance with their preferences. They had one week to prepare for the MCs.

Third, a questionnaire with multiple choices was implemented after the whole class finished MCs. They were asked to provides their opinions on their performance, their personal and professional growth after they participated into MCs activities. 
The reasons for using questionnaires as research instruments were because firstly, they would ensure a high response rate owing to the expected high number of participants attending the conference. Secondly, because the study was to take place in one location and during a determined number of hours, it would be inexpensive and quick. Thirdly, as opposed to other research instruments such as interviews, group discussions or surveys, questionnaires could ensure a better anonymity of the respondents and confidentiality of the data the respondents provide. Furthermore, compared to other research instruments and in relation to the type of study undertaken, questionnaires could ensure the integrity of the study (its validity and reliability) because they presented the fewest disadvantages. Those disadvantages were mainly self-selecting bias from student interpreters and the lack of opportunity to clarify issues when answering close-ended questions. For these reasons, both openended and close-ended questions were included in order to reduce bias and ensure the reliability of the data recorded, as open-ended questions were to enable respondents to expand on their answers. The overall objective for choosing this method was to enable both student taking a role as interpreters and students taking a role as conference delegates to provide first-hand input regarding the interpreting services rendered by student interpreters.

After the conference, the questionnaires were collected, the data gathered and analysed, and the results compiled in a report that formed the basis of the study. As a study involving human subjects, the need to obtain the consent of the participants was fulfilled by distributing consent forms before the conference and asking participants to complete them.

Students' scores on the pre-tests and post-tests were recorded and analyzed by SPSS version 22. SPSS calculated the mean, the median, standard deviation and correlation between the pretest and posttest's performance to accredit the Hypothesis.

\section{FINDINGS AND DISCUSSION}

More than two thirds of all participants agree that the mock conferences that they have been involved in as an interpreter are generally good learning experience. A third of the total show a strong approval. Only less than 10 percent state that the MCs neither good nor bad. This suggests that MC was generally perceived as an effective learning activity.

When asked about the experience perceived by students, around 20 students out of 35 reported that the MCs were enjoyable, satisfying and stimulating. Perhaps they would find out a number of perspectives of an interpreter that they had never gone through before, although these data are not presented in the bar chart. Noticeably, almost all students (34/35) regarded MCs as being beneficial. However, interpreting in front of public seems to be a challenging task for students, since a large proportion of the poll (30/35) admitted that MCs were hard. The fact that MCs were regarded as this way due to many factors. 
Firstly, they are still novice interpreters with limited prior contextualized practices, whose strategic and psychological competences were not adequate. Secondly, compared with traditional interpreting classes, MCs are much more challenging because they are comprehensive tests of participants' psychological competence, strategic competence, professionalism and many other competences. As novice interpreters, they were not mature enough to integrate all skills they had learned. Their involvement in MCs was a process of learning how to integrate interpreting skills in authentic tasks. This highlights the importance of using MCs in educational environments to prepare participants for the job market. The above explanations were based on the author's supposition of his knowledge about the trainee interpreters. It would be useful to have their feedback through interviews to triangulate the current findings in future efforts.

The reasons are explained more clearly in the feedbacks that students were asked to fill up after the MCs. Student XY: "I feel that the MCs are really hard and being an interpreter at an MC about climate change was a challenging for me. Some parts of the material that I need to interpret were not familiar to me"

When asked about whether the MCs are an enjoyable experience, 10 students totally agree with the idea, and more than double of this figure agree that MCs are an enjoyable activity, only three correspondents express a neutral opinion. Student XZ: "I felt pretty enjoyable because each presenter has a chance to deliver different content". Student A2: "What I like most about the MCs was that there were a lot of interesting topics, for example, leadership skills, emotional intelligence and photography. I feel that I have learnt a lot of skills and knowledge from attending the MCs". The opinions share by the students highlights the findings in research done by Lin, Davis and Liao in 2004 which states that the MCs can stimulates trainees' enthusiasm and autonomy.

When asked about whether the MCs are an satisfying experience, four students totally agree with the question posed, 21 attendees agree that the experience they got from MCs was satisfying, only four students express a neutral opinion. The reason can be seen more clearly from the following feedbacks. Student ZT: "Some interpreters were very confident. When they did interpreting, I felt like they were the presenters. Not only did they transfer the meaning of the talks, but they also convey the feelings, emotions, and the energy of the presenters. I was so interested in their performance and would give them two thumbs up. However, other interpreters were not successful enough, they drained our energy and prolonged the tiring atmosphere of the MCs". The source of dissatisfaction of this student comes from the professionalism and the quality of the interpreters of the conference. Student XT: "I do not really enjoy attending MCs, probably because of the fact that some interpreters have failed to explain and clarify some technical jargons. They have got a lot of problems in conjuring up phrases which should have been more understandable. Some topics, for example finance and bitcoin are way too technical for me. I feel that I was stressed out when trying to understand the content of topics". 
Vol. 4, Issue.6, Nov-Dec 2021, p no. 361-384

These student attend MCs as members of audience, and probably has a better command of English that the interpreter. They expect that some interpreters could have done better at delivering the messages. This reflects some of the findings of Derry and Lesgold in 1996, Herrington and Oliver in 2000, McLellan in 1996 and Yong in 1993 which state that the MC as a situated learning activity helps to develop an mutual relationship between learners. Students are encouraged to reflect and identify the distance between learners' level and expert' level and find ways to narrow it.

In response to the question of whether the mock conference is a beneficial experience, 18 students totally agree with the statement, 15 students agree and 1 student express a neutral opinion. These following feedbacks may help to explain the reason for a major approval. Student YZ: "After attending the MCs, I found that I could learn a lot from seeing my friend doing interpreting tasks. I could draw some lessons from my friends' mistakes. Sometimes they distract the audience with some of their strange body gestures, improper pauses during the talks". This student saw that MC is an opportunity for reflection. In normal lesson where students spend most of the time sitting in front of the computer and listen to video tape, they could hardly have any chances to focus their attention on others' performance. However, when they attend MCs, they can see their peers and friends doing interpreting. This reflect the finding in a research done by Manuel Jerez in 2006 which suggests that the effect of situated approach in interpreter training is that student's motivation is increased and motivated to learn. Furthermore, the Jerez recommends that students should be exposed to the rich and varied professional reality.

Student XT: "The MCs were really stimulating because it was the first time I had attended such a type of lessons that resembles what was happening out there. MCs were new to me and they offered me a better look of a real situation in which the interpreters worked.". The opinion is in line with research done by Herrington and Oliver in 2000; Hung and Chen 2002 which suggest that MCs can bring the benefits of situated learning to traditional classrooms because students can access to more authentic situations and maximize the efficiency of interpreting programmes in preparing interpreters for the market.

\subsection{What skills can be acquired better at MCs?}

The features of MCs and traditional interpreting classes were explained. The component skills were based on T\&I literature (Jiménez Ivars 2009; Kalina 2000). Since the MCs involved only consecutive interpreting, the skills were specific, though not unique, to consecutive interpreting. 
Table 4.1. Interpreting skills

\begin{tabular}{|c|c|}
\hline \multirow{4}{*}{$\begin{array}{l}\text { Bilingual } \\
\text { competence }\end{array}$} & $\begin{array}{l}\text { Analytical listening and } \\
\text { comprehension }\end{array}$ \\
\hline & $\begin{array}{l}\text { Delivery of message in Target } \\
\text { Language (TL) (public speaking, } \\
\text { etc.) }\end{array}$ \\
\hline & Monitoring of production \\
\hline & $\begin{array}{l}\text { Linguistic agility (resourceful } \\
\text { enough to cope with emergencies, } \\
\text { etc.) }\end{array}$ \\
\hline $\begin{array}{l}\text { Knowledge } \\
\text { competence }\end{array}$ & Subject-specific knowledge \\
\hline \multirow{2}{*}{$\begin{array}{l}\text { Cross cultural } \\
\text { communication }\end{array}$} & $\begin{array}{l}\text { Non-verbal communication (facial } \\
\text { expression, body language, etc.) }\end{array}$ \\
\hline & $\begin{array}{l}\text { Culture-specific strategies (culture- } \\
\text { loaded elements like idioms, etc.) }\end{array}$ \\
\hline $\begin{array}{l}\text { Transfer } \\
\text { competence }\end{array}$ & $\begin{array}{l}\text { Language-specific strategies } \\
\text { (strategies to render certain } \\
\text { syntactic patterns, numbers, terms } \\
\text { and pat phrases) }\end{array}$ \\
\hline \multirow{5}{*}{$\begin{array}{l}\text { Psychological } \\
\text { competence }\end{array}$} & Concentration \\
\hline & $\begin{array}{l}\text { Shared attention between listening } \\
\text { ahead and note-taking }\end{array}$ \\
\hline & $\begin{array}{l}\text { Shared attention between note- } \\
\text { reading and production }\end{array}$ \\
\hline & Being calm under pressure \\
\hline & $\begin{array}{l}\text { Mental agility (flexible enough to } \\
\text { cope with emergencies, etc.) }\end{array}$ \\
\hline $\begin{array}{c}\text { Strategic } \\
\text { competence }\end{array}$ & $\begin{array}{l}\text { On-site problem-oriented strategies } \\
\text { (compression, omission, addition, } \\
\text { etc.) }\end{array}$ \\
\hline \multirow{3}{*}{ Professionalism } & $\begin{array}{l}\text { Preparation (glossary building, } \\
\text { background information research, } \\
\text { team work, etc.) }\end{array}$ \\
\hline & $\begin{array}{l}\text { Professional ethics (dress code, } \\
\text { behaviour, etc.) }\end{array}$ \\
\hline & $\begin{array}{l}\text { Self-reflection (weaknesses, } \\
\text { strengths, etc.) }\end{array}$ \\
\hline
\end{tabular}

The top highly ranked skills included preparation, subject-specific knowledge, self-reflection on the performance, being calm under pressure, non-verbal communication, concentration, share attention 
between note-reading and production, shared attention between listening ahead and note-taking, professional ethics. In the chart, it can be seen that 27 out of $35(80 \%)$ agree that the preparation work such as building glossary, investigating the background knowledge by reading material before the MCs was more demanding than traditional classes. 24 attendees agree that MCs ae better at providing the participants the opportunity to build up specific knowledge. In some MCs, students who participate as presenters and interpreters have to spend an extended time, for weeks for example, to prepare for the MCs. They have to read and prepare a lot of questions that can be asked by audience.

This somehow reflects the true nature of MCs which are meant to promote professionalism, selfreflection, psychological competence (how to stay calm under pressure) and non-linguistic skills (nonverbal communication, body gestures, etc.) These competences and skills tend to be acquired better when students are put into context. (Jiménez Ivars 2009; Kalina 2000). Also, the result could be seen in more detailed in the feedbacks of some students. Student ZT: "Apart from specific knowledge gained after each MC when I have to prepare a lot of documents, translating beforehand, I feel that the MCs were better than the conventional classes in many aspects. For example, during MCs, I learn how to present in front of class and how to take a control of my voice, body gestures and interact with the audience". This student stresses on the significance of preparation and non-verbal communication. In the traditional classroom setting, students do not focus on dress code and behaviors when delivering the message, however, in MCs when they have to stand in front of the pulic, and they must do roleplaying, the dress code is important since it tells audience that which role the speakers are playing, and which roles that the intepreters are playing.

It can be seen that 23 students agree that they acquired the skill "Being calm under pressure" better at MCs than traditional classes, 22 attendees agree that the skill "share attention between listening ahead and note-taking" was better developed at MCs than traditional classes that focuses on listening skills. 21 participants agree that their "concentration skill" was better fostered in MCs. 17 students rate "share attention between note-taking and production" was better acquired at MCs than traditional classes. Student YT state: "After preparing and translating a lot of documents about Google Ads, I know how the system work and the usage of Google Ads. I can differentiate various types of Google Ads. After being an interpreter, I gained more skills related to note-taking and public speaking. I feel that I have picked up one skill that was important, that is to distribute the time spent on reading notes and looking at the audience. The attention should be balanced as the audience would feel a distance between me and them if I focused too much on the notes". This student benefits from the subject-related knowledge and the shared attention between the note and production. Another evidence can be seen from student ZZ: "After interpreting the talks concerning "Public Speaking", I understand how important of the preparation and practice for a presenter. From that, I could learn the lesson of staying focused, being confident and using body languages. In terms of self-reflection, after listening to my friends' comments, I acknowledge that I need more practice, courage to be more resourceful when being an interpreter". This student lays stresse on the importance of prep-work and metal agility. These results 
reflect the findings proposed by Fernadez Prieto and Sempere Linares in 2010 who theoried that psychological competence depends on context and better achieved through contextualized practice.

Other linguistic skills such as language-specific strategies, delivery of message in target language, and culture-specific strategies are more context-independent, and can be achieve in a less contextualized environment; for example, traditional interpreting classes. This is consistent with the author's proposal to place emphasis on competences that can be developed in a less contextualized setting at early stages of training in traditional interpreting classes.

In the feedback session, students have provided a lot of insights into their experience and reveal some explanation for their comparison between MCs and conventional interpreting. Student B4: "After listening to feedbacks from the council, I can acknowledge that I have made a lot of mistakes that I previously unaware of, for example, when I was talking, I tended to use many pauses, which could disrupt the flow and badly influence my fluency. I will try my best to improve my mistakes". This student concerns about the importance of self-reflection. Student B5: "After MCs, I have gained a lot of specific knowledge concerning different types of topics. However, I feel that the best part of the MCs was that I could learn

Figure 4.17: Post-test experimental group

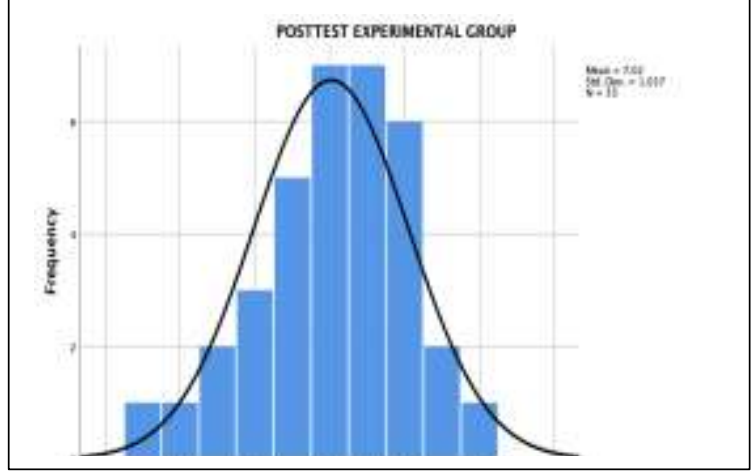
how to focus on the main ideas of the talk. It is unnecessary to pay attention to all words of the talks, but to select the key points.". The skill that this student gain is on-site problem-oriented strategies (know how to omit unnecessary parts and add more explanatory ideas into their own production).

However, there are some skills that less than a half of the poll feel that MCs are better than traditional classe. Such skills as monitoring of your own production, and language-specifice strategies catch attention from 11, 13 students respectively. The result indicate that the traditional classes may be better at helping students to acquire these skills.

\subsection{Assessment}




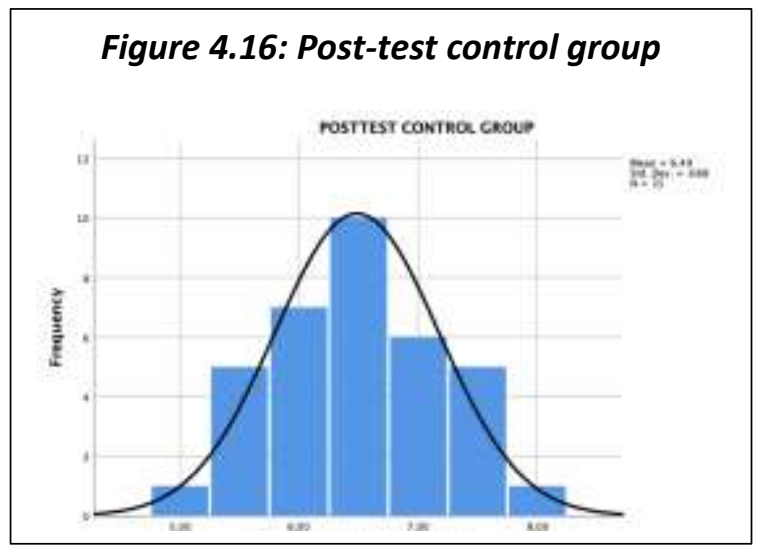

In order to evaluate impartially, two experienced lecturers from the Department of Foreign Languages, Vinh University were invited to grade the students' performance. At first, all students listened to a three-minute talk. After that, they would interpret consecutively the talk which had been divided into chunks of information. The audios were then collected and sent to two teachers for assessment. Following this, for each student, his or her score would be the average of the sum of two scores marked by two teachers. If the difference between the marks provided by two teachers were greater than 01 , the audio would be re-evaluated by the author.

In order to evaluate the performance of students subjectively, a rubrics developed by NAATI which is the national standards and certifying authority for translators and interpreters in Australia was adapted.

As can be seen from the rubrics, transfer competency and language competency were the focus of this evaluation. While transfer competency concentrates on assessing meaning transfer skills (the skills that the interpreter needs to master to deal with the techniques of omissions, insertions and distortions), application of interpreting modes and rhetorical skills (such skills as voice projecting, pronouncing the words, and using the rhetorical techniques: for example: repetition, reversal, substitution), language competences highlights the language proficiency which enables meaning transfer.

In total, we received 140 audio files from 70 students who participated in the experiment. 35 audio files collected from the control group yielded a mean of 6.46 and a standard deviation of 0.818 . The result is shown in the diagram bellow. It can be seen that the data are normally distributed in which the charts form a bell curve.

35 audio files collected from experimental group yielded a mean of 6.55 and a standard deviation of 0.819 . The result is shown in the diagram bellow. It can be seen that the data generally are normally distributed, in which the charts form a bell curve.

35 audio files collected from 35 students from the control group after the treatment yielded a mean of 6.49 with a standard deviation of 0.688 . 


\section{International Journal of Education and Social Science Research}

ISSN 2581-5148

Vol. 4, Issue.6, Nov-Dec 2021, p no. 361-384

It can be seen that the data generally are normally distributed, in which the charts form a bell curve. 35 audio files collected from 35 students from the experimental group after the treatment yielded a mean of 7.02 with a standard deviation of 1.037 .

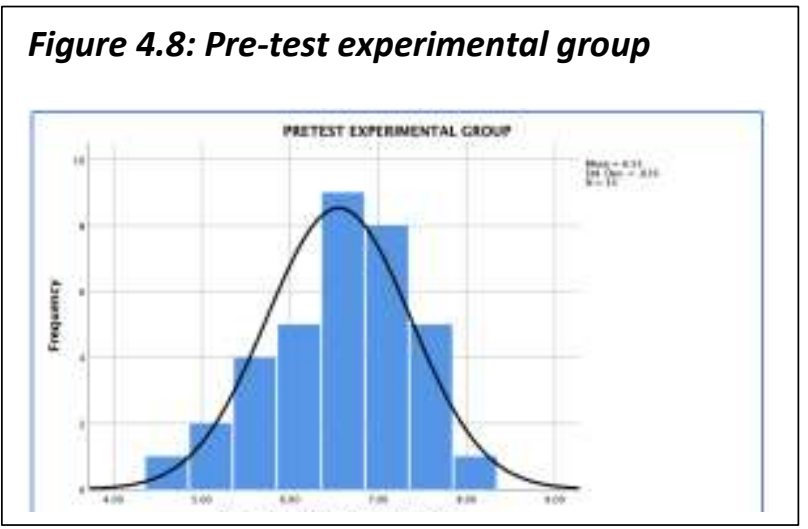

SPSS was used in order to measure the strength of the relationship varies in degree between the students' grades after the treatment. A value of 0.847 shows that there is a strong relationship between the two variables from the experimental group.

To answer the hypothesis whether MCs had any significant influences on improving students' interpreting competencies, the author used SPSS version 25 to run a paired-samples T-test. It can be seen that the value of Sig. for Pair 2 (Experimental group) is $0.000<0.05$. It means that there is a statistically significant difference between the means of two variables. For Pair 1 (Control group), the value of Sig. is $0.862>0.05$. It means that there is statistically no difference between the means of the two variables from the control group.

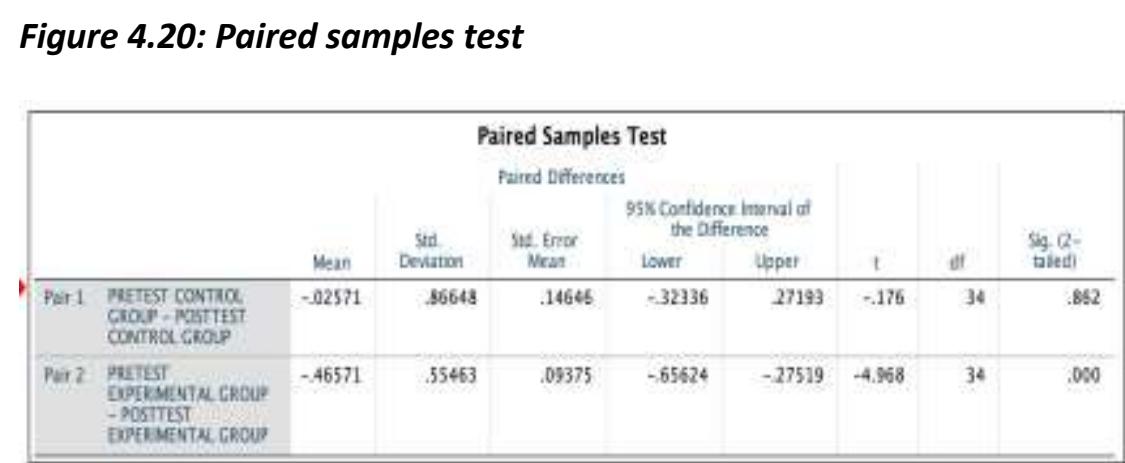




\section{CONCLUSION}

This study was intended to inform interpreter trainers about the theoretical foundations of using MCs as situated learning activities and their design principles and procedures, and to probe into trainees' ratings of interpreting at MCs as learning experiences, benefits of MCs in helping trainees acquire skills, their advantages and disadvantages compared with traditional interpreting classes, and spaces for improvement in design.

The results indicate that, though MCs seemed to be challenging tasks, trainees perceived them as good, beneficial and stimulating learning experiences and that the statistics shows that MCs can improve student's interpreting performance. The findings also suggest that skills related to professionalism, psychological competence, strategic competence and many other non-linguistic dimensions might be better acquired at MCs than in traditional interpreting classes. This concurs with the perceived advantages of MCs mentioned by the participants. As for the disadvantages of MCs, most were related to the organisation of MCs, suggesting that authentic and confidence-building learning experiences come from well-designed MCs. The participants suggested improving the authenticity and pedagogical progression, and videotaping their performances for future reflection, to improve the current $\mathrm{MC}$ design.

This study may contribute to knowledge on the theoretical justifications and empirical evidence of the usefulness of MCs in interpreter training. It is hoped that it can provide insights into the use of MCs for colleagues to better prepare their students for future professional life.

The limitations of this study lie in its sample size and means of data collection. This study focused on a specific group of trainees in a specific teaching context. Further research that includes a wider representation might yield more generalisable results. Although questionnaires are widely used in researching students' perceptions of teaching approaches, triangulation of data collection combining both questionnaires and in-depth interviews may provide more food for thought.

\section{BIBLIOGRAPHY}

Nguyen, Ngoc Thi Nhu. Survey on the situation of training translation and interpreting at some universities in Vietnam. Teaching Translation and Interpreting in Vietnam. Ho Chi Minh: Ho Chi Minh Vietnam National University, 2016.

Pham, Ho Vu Phi. "Instructional model in teaching translation and interpretation: A case Study." Journal of Science HCMC Open University (2015): 84-94.

Pöchhacker, F. "The role of theory in simultaneous interpreting." Teaching Translation and Interpreting: Training, Talent and Experience. (1992): 211-220.

Pöchhacker, F. Introducing Interpreting Studies. London and New York: Routledge., 2004.

Access 2 Interpreters. Access 2 Interpreters. 742014.

$<$ https://www.access2interpreters.com/history-language- 


\section{International Journal of Education and Social Science Research}

Vol. 4, Issue.6, Nov-Dec 2021, p no. 361-384

interpretation/\#: :text=Language $\% 20$ interpreting $\% 20$ is $\% 20$ known $\% 20$ to,reference $\% 20$ to $\% 2$ 0an\%20interpreter\%20supervisor.>.

Tien, Le Hung. "On a theoretical foundation for professional translator and interpreter training and eucation for Vietnam." Journal of International studies (2017): 105-117.

Tran, Thi Thu Trang. "Teaching interpretation at school of foreign languages: A brief evaluation and some activity examples." TNU Journal of Science and Technology (2019): 23-29.

Hatim, Basil and Ian Mason. The translator as Communicator. London: Routledge, 1997.

Setton, Robin. "Context in simultaneous interpretation." Journal of Pragmatics (2006): 374-389.

Li, Xiangdong. "Mock conference as a situated learning activity in interpreter training: A case study of its design and effect as perceive by trainee intepreters." Routledge - the Interpreter and Translator Trainer (2015).

Herrington, Jan and Ron Oliver. "An instruction Design Framework for Authentic Learning Environment." Education Technology and Research Development (2000).

Lin, Wei. "Why Do Students Learn Interpreting at the Graduate Level?" T\&I Review 3 (2013): 145168.

Lin, J, C Davis and P Liao. "The effectiveness of Using International Mock Conference in Interpreting Courses." Studies of Translation and Interpretation 9 (2004): 81-107.

Setton, Robin. "Context in simultaneous interpretation." Journal of Pragmatics 38 (2006): 374-389.

Vinh University. Vinh University. 1 January 2019. <http://vinhuni.edu.vn/gioi-thieu>.

Department of Foreign Languages. FLD. 122019.

$<$ http://englishdept.vinhuni.edu.vn/about/departement-of-foreign-languages/seo/departmentof-foreign-languages-74399>.

Nguyen, Phuong Lan. Outline of Interpretation I. Vinh: Vinh University Publisher, 2017. 